\title{
Quality improvement in teaching and learning science in primary school settings: Using a metaphor to approach the concept of light
}

\author{
James Rodriguez $^{1 *}$, David Castro ${ }^{2}$ \\ ${ }^{1,2}$ Researches, MSc in Education, Primary Education, Denver, Colorado, USA \\ *Corresponding Address: jamerodr@gmail
}

\begin{tabular}{|c|c|}
\hline Article Info & ABSTRACT \\
\hline history: & \multirow{4}{*}{$\begin{array}{l}\text { The present study focuses on the approach of the concept of light by primary } \\
\text { school students. The study explores how a teaching procedure founded on } \\
\text { using the metaphor that light travels as a wave reflects on the concept of light } \\
\text { as a distinct natural entity. The experimental method was used for the } \\
\text { research. One hundred and fifty-two children aged between } 7 \text { to } 8 \text { years old } \\
\text { (average age } 7.59 \text { ) from } 9 \text { different primary school classes in Colorado, USA, } \\
\text { participated in the research. An experimental and control group was } \\
\text { delineated. Following a socio-cognitive perspective, the experimental group } \\
\text { took part in a teaching procedure based on using the metaphor that light } \\
\text { travels as a wave. Following an empiricist perspective, the control group took } \\
\text { part in a teaching procedure based on a description of the phenomenon } \\
\text { without using a metaphor. Data had been collected through pre and post-test, } \\
\text { which results were analyzed using the Mann-Whitney test. The quantitative } \\
\text { analysis showed an essential difference between the two groups. The } \\
\text { experimental group pupils achieve higher learning outcomes as they better } \\
\text { understand light as a distinct entity. It is argued that using a metaphor allows } \\
\text { children to make connections with their everyday life, wonder about, and } \\
\text { conceptualize light in a more efficient and meaningful way. The study informs } \\
\text { everyday educational practice by providing a quality improvement element } \\
\text { for learning and teaching about the primary classroom light. }\end{array}$} \\
\hline $\begin{array}{l}\text { Received: March } 31^{\text {st }}, 2020 \\
\text { Accepted: June } 15^{\text {th }}, 2020\end{array}$ & \\
\hline Keywords: & \\
\hline $\begin{array}{l}\text { Light; } \\
\text { Metaphor; } \\
\text { Primary education; } \\
\text { Pupils' alternative conceptions; } \\
\text { Science education. }\end{array}$ & \\
\hline
\end{tabular}

(C) 2020 Physics Education Department, UIN Raden Intan Lampung, Indonesia.

\section{INTRODUCTION}

A clear aspiration for children's advanced learning outcomes in science throughout school life is highlighted through curriculums, pedagogical handbooks, and policy documents anywhere in the world. Changes in children's learning outcomes require an improvement in teaching and learning interventions that are more efficient and meaningful to young children. Students' thinking about science concepts and phenomena has been widely discussed in the framework of Science Education research (Fratawi et al., 2020; Latifah et al., 2018; Saregar et al., 2018; Sotirova, 2017; Tin,
2018). What is known from the longstanding research in the field is that also young children have a wide range of alternative conceptions, mental representations, misconceptions, ideas, and arguments about the physical and technical world that surrounds them (Elmali \& Şimşek, 2020; Fragkiadaki \& Ravanis, 2015; Herakleioti \& Pantidos, 2016; Kaliampos \& Ravanis, 2019). Despite the uniqueness of young childrens' thinking in science, the literature has indicated that their thinking is not accordant with the scientific models used in early years education when children enter school life. Research has shown that 
children's thinking about the phenomenon is not in line with the Physics model. From an educational perspective, this emphasizes the necessity for organizing appropriate teaching and learning interventions for achieving qualitative changes in young children's thinking (Adbo \& Carulla, 2019; Fragkiadaki \& Ravanis, 2016; Pereira et al., 2020).

The study explores how a teaching procedure founded on using the metaphor of light traveling as a separated "object" positively affects students' thinking about the comprehension of light as a distinct natural entity. An experimental group (from this point, it will be referred to as EG) and a control group (referred to as CG) was delineated in a constructivist, sociocognitive, and an empiricist approach, respectively (Ravanis, 2017).

Following a socio-cognitive perspective, the EG took part in a teaching intervention founded on a metaphor. We could define metaphor as a mental tool that uses a comprehensible state of the elements and the relationships between them to understand a new state (Giren, 2016; Onen Ozturk \& Aglarci, 2017).

Following an empiricist perspective, the CG participated in a teaching intervention based on a traditional description of the phenomenon without using a metaphor. However, traditional teaching also has some critical features of students' and teachers' practices. In a traditional classroom, the student awaits to transfer the new information from the teacher. The teacher's usual practices are the transfer of new information, the exercise of the students, and the standardized control of the students for the acquisition of the new knowledge (Bigozzi et al., 2018). A comparative qualitative analysis followed.

The study begins with a review of what is known about young children's conceptions about light, where specific obstacles in children's thinking are identified. This is followed by a theoretical framing about compatibility between young children's thinking in Physics and the scientific model used in Early Childhood Science Education. The methodology for the twofold research procedure is explained in detail, and the quantitative results are discussed. The study argues that using a metaphor allows children to make connections with their everyday life, wonder about, and conceptualize light in a more efficient and meaningful way. The study informs everyday educational practice by providing a quality improvement element for instruction about the concept of light in school settings. The study concludes by stressing the need for an update in Science Education for early years, suggesting a teaching-oriented model towards an alternative conception of learning.

\section{The Transitive thinking and the Scientific Concept of Light: A Constructivist Perspective}

Transitive reasoning is a form of logicomathematical thinking. For example, if we know that $\mathrm{X}>\mathrm{Y}$ and $\mathrm{Y}>\mathrm{Z}$, then we can conclude without being told than $X>Z$., You can replace "greater than $(>)$ " with any other transitive relation. As argued by Piaget (1971), transitive thinking is the recognition that "if $X \rightarrow Y$ and $Y \rightarrow Z$, then $X \rightarrow Z$."

Transitive thinking was first identified as logical-mathematical knowledge. However, natural entities (e.g., heat, sound, or energy) that start from a source, propagate in space, and end up somewhere, can be understood as natural transitions of two steps. This kind of thinking is named "operational transitivity" (Piaget, 1971). This article will study the "operational transitivity" effect for the light as a distinct "object" in space. Indeed, as Ravanis (2012) suggested, for a student at the pre-operational stage of thinking, light is recognized on visible lighted areas (ViLiAr) and light sources (LiSo) or both via reasoning of the direct transition of the following form: LiSo $\rightarrow$ ViLiAr. Consequently, at this level, the child does not recognize the space in which light beams transmit, or in other words, the space of light's propagation (SpPrLi). However, a specific form of logico-mathematical transitivity highlighting 
operational thought: $\mathrm{LiSo} \rightarrow \mathrm{SpPrLi}$ and $\mathrm{SpPrLi} \rightarrow \mathrm{ViLiAr} \rightarrow$ LiSo $\rightarrow$ ViLiAr.

This Piagetian theoretical scheme functions as a general model for understanding the propagation of invisible natural entities produced in specific sources. On this basis, the conception of light constructed on transitivity imposes on thought the propagation in two phases. For each phase, the recognition of the existence of light in space is necessary.

\section{Young Children's Conceptions about Light}

The theoretical composition of Geometric Optics is an appropriate framework to conceptualize a series of concepts and phenomena related to light and its interactions with matter. So, very often in research looking for the reasoning of students on issues such as rectilinear propagation of light (Castro, 2018), shadows formation (Grigorovitch \& Nertivich, 2017; Voutsinos, 2013), the vision (Ravanis, 2018; Sotirova, 2018).

In this perspective, the challenge of understanding light as a distinct entity diffused separately from the light source and transmitted in space has previously been known in several types of research focusing on primary and secondary school students. What is known from this empirical research is that student thinking is concentrated more on objects that produce light or in highly lit areas or spots where light ends and is easily "visible" due to reflection and diffusion (Castro \& Rodriguez, 2014; Grigorovitch, 2015).

In that framework, specific teaching procedures were intended using methods of particular teaching exchanges. The class settings can assist students to construct the conceptions which they do not have or create the conditions for the construction, deconstruction, and reconstruction of their scientific thinking about the light in a way that is accordant with the scientific model (Grigorovitch, 2014; Ravanis et al., 2013; Rodriguez \& Castro, 2016).
In this research, the hypothesis formulated is that the comparison between two different teaching strategies makes it possible to highlight that a specific metaphor can support students transform a pre-operational alternative conception of light into a Physicsaccordant operational conception.

\section{METHODS \\ Sample}

One hundred and fifty-two (152) students (74 boys and 78 girls) from 7 to 8 years old (average age 7.59) participated in the study. The students were recruited from nine (9) different primary school classes. In this study, the convenience sampling method was used to select schools and classrooms (Bryman, 2016).

All nine classes, located in semi-urban areas, were in Denver, Colorado, in the United States of America. Student performance was distributed across the score spectrum. Students came from families of all social levels, and they were randomly separated into two (2) groups of seventy-six (76) children each that is the EG and the CG.

\section{The Research Procedure}

For the research we present here, the experimental method was used. The research was conducted with two groups of students (EG and $\mathrm{CG}$ ) in three phases (pre-test, teaching interventions, post-test).

The research design was oriented towards realizing a teaching procedure based on the use of a metaphor to support students' comprehension of light transmission. The teaching intervention's anticipated outcomes were to position students able to construct a model for understanding the concept accordant to the scientific one used in the early years of science education. In line with the Geometrical Optics model, the intervention aimed to shift students' thinking from a pre-operational model of thinking towards an operational model of thinking. A metaphor from children's everyday life was used. According to Ravanis et al. (2013), an appropriate tool for understanding light is the 
metaphor of light traveling in space. An EG and a CG were delineated and a comparative quantitative analysis followed between the two groups.



Figure 1. The Experimental Design

In line with the findings of short pilot research, the general design consisted of three phases: (1) a pre-test data collection, (2) teaching procedure, (3) post-test data collection. Both groups, the EG, and the CG participated in the three phases.

\section{The tasks}

During (a) and (c) phases, students participated in a set of three tasks. The description of the three tasks follows.

- Task 1: The task took place in a room with light rays from the sun. Students were asked to indicate to three or more points where "there is light." The students were then encouraged to give many answers. The task aimed to confirm whether or not students could recognize light as a distinct entity inside the room.

- Task 2: In the second task, we use an electric pocket lantern. We emit a beam of light on a wall, and a bright circle is formed there. When the lamp was on, the student was asked the following question: "Where is the light from the torch?" If the student indicated the lit spot and the torch's lamp, children were in add asked the following question: "In the air, is there any light between the torch and the surface of the wall?". The task's aim was for the student to respond without using his/her vision because vision-based can give an answer that comes from merely concentrating on the bright circle on the wall and not from transitivity thinking.

- $\quad$ Task 3: In the third task, we use the following experimental setup. On the table are two cards (A and $\mathrm{B}$ ). On card A, a circular hole was cut out. Opposite the hole, there is a table lamp (L), as illustrated in the following figure (Figure 2).

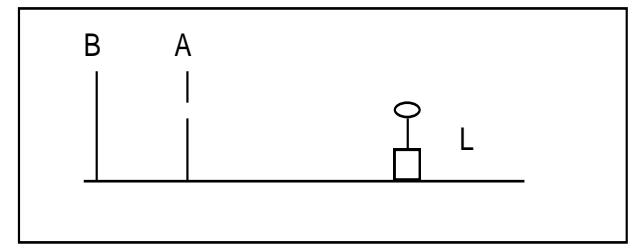

Figure 2. The Arrangement of the Objects in Task 3

The set was presented to the students. Then, the lamp was turned on. At that point, students were asked: "Is there any light from the lamplight between the two cardboards?". If the student answers that "there is light," we ask them to explain their thoughts in detail. In the case the answer was negative, children were in add asked the following question: "In the air, is there any light from that lamp?". The aim here was to investigate whether students can recognize the light not visible as a distinct entity in space. If this happens in an unusual task, it seems that children go beyond their concentrations, use a transitional schema of reasoning. Because if this is indeed the case, they have the cognitive conditions to approach the representation of Geometric Optics.

\section{The Experimental and the Control Group}

The teaching and learning intervention phases differ for the two groups. The fundamental difference between the two 
procedures was the absence of the use of the metaphor.

During the EG intervention, the metaphor led the communication and the interactions between the teachers and the students. The intervention in the EG aimed to create conditions for the students to shift their thinking from a pre-operational alternative way of thinking towards an operational conception of thinking about light transmission through the use of the metaphor. The intervention was held with groups of three (3) to five (5) children. The duration of the teaching intervention was the same as the original primary classroom settings.

Based on Ravanis (1999), students use a light comprehension scheme that connects the light source and its receiver without intermediaries. That is why in the EG, we tried to go to a form of understanding that necessarily goes through the path that light makes. Indeed, here we have tried to lead students' thinking from a misconception to a model in which light is recognized as a distinct entity. With this aim, we questioned the EG students: a) "Where does the light come from?". b) "How does the light come to us?" During the discussion with the students, we use the metaphor "trip of light from the source to the wall." In contrast, around this metaphor, we place all the elements of the model of Geometric Optics (sun as a source, a voyage in space towards other planets or lamp as a source, travel through space towards us) and the relationships that connect them.

Also, to help students perceive light as a distinct natural "object," we talked about the sun's rays, their course in space, their approach to the Earth's atmosphere, their passage through the clouds, and their arrival on Earth's surface, using at the same time the terms "rays," "beams" and, "light."

We then tried to connect the light with everyday life, working with students based on a picture and a sketch showing light beams accentuated. We debated with them the light shown in the illustrations and the idea that there is no light in space. This discussion aims to lead students to understand the contradiction. Then we are discussing the "travel of light" concept again and thus complete our teaching intervention.

During the CG intervention, the children attended a teaching intervention where an empiricist procedure was accurately taking place. The teaching process was based on the phenomenon of sunlight reaching the Earth but without reference to the "travel" metaphor. The operation and role of light sources in light production were discussed in detail, and the sun was identified as an essential source of light. Thus, the self-lit and hetero-lit light sources were distinguished.

Throughout the educational process, teaching materials such as photographs, images, three-dimensional objects (the sun and the planets, small light sources sometimes in operation, and sometimes not) were used systematically.

\section{Data Collection}

During the three phases, data regarding students' conception of light's phenomenon were collected through individual interviews. The average duration of these interviews was thirteen (13) minutes. The interviews with the students took place in the school's science laboratory. The interviews were recorded to be analyzed. During the interviews, students were asked to express their thinking regarding the concept of light transmission for all three tasks. The pre-test interviews were conducted 1.5 months before the two teaching procedures, and the post-test interviews were conducted 1.5 months after the teaching.

\section{Criteria of Evaluation}

Between the pre-test and the post-test, the students' mental representations were compared as they were expressed in their answers. So, we have answers that suggest a transition from a pre-operational misconception in the pre-test to an operational answer compatible with the model of Geometric Optics in the post-test (progress). We also have answers to which 
the basis of reasoning expressed before and after teaching remains constant (immobility).

\section{RESULTS AND DISCUSSION}

In the research, we work with two independent samples of randomly selected students by the same population. The MannWhitney test was used to compare the possible differences in students' reasoning between pre-test and post-test. This comparison was made at a level of statistical significance of 0.05 .

As we have already analyzed in the research, we had two groups and performed two tests (pre- and post-tests) for each group. In all the students' answers, two-level reasoning was identified: hose that recognizes the light in space and is compatible with Geometric Optics (category $\mathrm{C})$, and those that recognize the light in sources and brightly lit spots and are incompatible with Geometric Optics (category I). The frequencies of the students' answers are presented in Table 1.

The qualitative analysis of the responses showed the following:

C) In this category of answers, the main feature of reasoning is the recognition of light in space, where the interaction of light with air does not leave any visible trace. For example, "We can't see it.... it's all around us ..." (Task 1, subject 132). "It starts from the lamp .... it flies in the air .... and goes to the wall (shows the route manually)" (Task 2, subject 28). "The light from the lamp will go to the wall .... but it will be in between because it passes through... (the children show the direction of light)" (Task 2, subject 37). "As I told you before with the torch, the light will start from the lamp and pass through the hole to reach the other cardboard. If the lamp is lit there will be light between the two cardboards..." (Task 3, subject 37).

I) In this category of answers, students do not recognize the light in the air, but in light sources and objects in which there is a vital trace of light. "The light? We see it on the floor" (Task 1, subject 98). “....So the light is on the lamp of the torch and on the wall opposite" (Task 2, subject 119). "The light when passed through the hole will fall on the second cardboard. Between the two there will be no light ...... there is air ..." (Task 3, subject 113).

Table 1. Frequencies of EG and CG Students' Answers in Three Tasks

\begin{tabular}{cccccc}
\hline & & \multicolumn{2}{c}{ PRE-TEST } & \multicolumn{2}{c}{ POST-TEST } \\
\hline & & EG & CG & EG & CG \\
\hline \multirow{2}{*}{ Task } & Cat. C & 6 & 5 & 42 & 10 \\
\cline { 2 - 6 } $\mathbf{1}$ & Cat. I & 70 & 71 & 34 & 66 \\
\hline \multirow{2}{*}{ Task } & Cat. C & 25 & 24 & 46 & 31 \\
\cline { 2 - 6 } $\boldsymbol{2}$ & Cat. I & 51 & 52 & 30 & 45 \\
\hline Task & Cat. C & 14 & 16 & 47 & 21 \\
\cline { 2 - 6 } $\mathbf{3}$ & Cat. I & 62 & 60 & 29 & 55 \\
\hline
\end{tabular}

In the pre-test, category $\mathrm{C}$ answers were for the three tasks, respectively 6,25 and, 14 for EG and 5, 24, and 16 for CG. In the posttest, the respective answers' frequencies were 42, 46, and 47 for EG and 10, 31, and 21 for CG. The answers given by the students of both groups in the pre-test were equivalent. In contrast to the post-test, the students' responses in the EG were much better than those of the students in the CG.

Changes in the responses of the students of the two groups between pre- and post-tests are recorded in Table 2 . The modifications in the children's estimations seem to confirm the hypothesis of the research. In the first task, the EG children showed more progress than those of the CG. In all three tasks, the differences between the two groups are statistically significant (task 1: $U=2120$, $\mathrm{p}<0.001$, task 2: $\mathrm{U}=2632, \mathrm{p}<0.02$, task 3: $\mathrm{U}=2219, \mathrm{p}<0.002$ )

The results of Table 2 and their statistical processing show that the EG group students can recognize light as a distinct entity in air more than that of the students of the CG. 
Table 2. Frequencies of Changes in Students' Responses between the Two Tests (preand post-)

\begin{tabular}{cccc}
\hline & & \multicolumn{2}{c}{ PRE-TEST / } \\
& \multicolumn{2}{c}{ POST-TEST } \\
\hline & EG & CG \\
\hline \multirow{2}{*}{ Task 1 } & Progress & 36 & 5 \\
\cline { 2 - 4 } & Immobility & 40 & 71 \\
\hline \multirow{2}{*}{ Task 2 } & Progress & 21 & 7 \\
\cline { 2 - 4 } & Immobility & 55 & 69 \\
\hline \multirow{2}{*}{ Task 3 } & Progress & 33 & 5 \\
\cline { 2 - 4 } & Immobility & 43 & 71 \\
\hline
\end{tabular}

In the first task, it is evident that there is significant progress for the EG students, in that it is related to the comprehension of the distinct presence of light in an everyday situation. The post-test seems that the focus on brightly lit places or/and light sources declines. One and a half months after teaching, a significant proportion of EG children can quickly spotlight in the room air.

In the second task, a simple electric pocket lantern was used, that is, a daily condition. Also, in this task, the students of EG have significant progress about the children of CG. Of course, as can be seen from the results, the children of $\mathrm{CG}$ also made progress with the pre-test. Perhaps the nature of the task, which directly refers to an occasion in everyday life, allowed the dominance in their thinking of a familiar image. In any case, their progress was significantly lower than that of EG students.

In the third task, the confirmation of the hypothesis is of real interest. In this task, we used an unfamiliar condition for students' everyday experiences. The EG student achieves to recognize light in-between the cardboard. This reasoning is created on a conception of the phenomenon deconcentrated from the need for visual identification of light.

In this research, we tried to show in a constructivist/socio-cognitive theoretical framework that the initiation of students 7-8 yers-old in some sides of the physical world is possible in the direction where primary school pupils construct a conception accordant with the characteristics of
Geometrical Optics framework. The data in this research show that students who participated in a socio-cognitive teaching intervention transform their pre-operational alternative conceptions much better than those who participated in an empiricist teaching procedure since the experimental group students understand light much better as a distinct entity. This finding is consistent with the results of previous studies conducted with students up to 10 years of age (Grigorovitch, 2014; Ravanis et al., 2013; Rodriguez \& Castro, 2016).

However, these results are also closely linked to the socio-cognitive teaching strategy. This strategy is a framework dominated by teacher-student interactions, which are based on knowing children's real difficulties. Thus, research data is utilized in a specific and detailed design whose purpose is to destabilize the alternative conceptions and construct the new knowledge that is accordant with the scientific own. In light comprehension in 7-8 years, these alternatives conceptions correspond to preoperational thinking, but in other cases, they are operational but at a distance or in contrast to scientific models.

Still, the transformation of alternative conceptions is closely related to using a metaphor, the travel of light into space. It is perhaps a typical case where a metaphor has a beneficial effect on learning a particular concept of the natural sciences. This metaphorical concept also fosters interaction between teachers and students as it provides a basis for developing dialogues, exchanging cognitive tools, and formulating arguments.

\section{CONCLUSION AND SUGGESTION}

This research has shown the importance of using a metaphor in the conceptual change for light, from the alternative pre-operational conceptions in the construction of a reasoning pattern that agrees with the framework of Geometric Optics. Indeed, it seems that this procedure can lead students to drive their cognitive tools to a higher level. This conceptual change that we found to be 
achieved may have been due to the sociocognitive framework we worked with the EG. In such a context, both the use of metaphor and the planned and implemented teacher-student interactions is reasonable to assume that it contributes to overcoming student barriers and transforming their initial misunderstandings.

From a pedagogical perspective, we cannot claim that this particular metaphor can make progress in children's thinking about all transmitted entities such as heat or sound. However, in a context like Early Childhood Science Education and Science Education in general, research interest is not just children's mental function. Also critical is the study of the effectiveness of specialized teaching situations and the analysis of the results of the teaching interactions (which was not the subject of this article).

Consequently, since our goal is to link changes in children's thinking to didactic design systematically, it is particularly interesting to seek to study a sociocognitive/constructivist didactic strategy and even in comparison with a traditional empiricist strategy.

As it became clear from the research's overall design, this study orientation for learning and teaching recognizes the primary importance of alternative conceptions in students' thinking. This option, which is usually associated with older children, seems to be of interest to younger children. Finally, considering that the experimental teaching intervention took place in experimental conditions with small groups of students, it would be exciting to transfer this procedure to real classrooms and check its width at the level of everyday didactics practices. Nevertheless, this is a question of great importance for future research.

\section{AUTHOR CONTRIBUTIONS}

JR concepting, and reviewing literature. DC edited the manuscript. JR and DC collected, analysed data and wrote the manuscript.

\section{REFERENCES}

Adbo, K., \& Carulla, C. V. (2019). Designing play-based learning activities in the preschool environment. Chemistry Education Research \& Practice, 20(3), 542-553.

Bigozzi, L., Tarchi, C., Fiorentini, C., Falsini, P., \& Stefanelli, F. (2018). The influence of teaching approach on students' conceptual learning in Physics. Frontiers in Psychology, 9, (8) 1-14.

Bryman, A. (2016) Social research methods. Oxford: Oxford University Press.

Castro, D. (2018). L'apprentissage de la propagation rectiligne de la lumière par les élèves de 10-11 ans. La comparaison de deux modèles d'enseignement. European Journal of Education Studies, 4(5), 1-10.

Castro, D., \& Rodriguez, J. (2014). 8-9 year old pupils' mental representations of light: Teaching perspectives. Journal of Advances in Natural Sciences, 2(1), 40-44.

Elmalı, Ş., \& Şimşek, C. L. (2020). PreSchool children's opinions about the concepts of floating, and sinking and the effect of in-class interactions on their opinions. Hacettepe Üniversitesi Ĕ̈itim Fakültesi Dergisi. Advance Online publication. doi: 10.16986/HUJE.2020058755

Fragkiadaki, G. \& Ravanis, K. (2015). Preschool children's mental representations of clouds. Journal of Baltic Science Education, 14(2), 267274.

Fragkiadaki, G. \& Ravanis, K. (2016). Genetic research methodology meets Early Childhood Science Education Research: A cultural-historical study of child's scientific thinking development. Cultural-Historical Psychology, 12(3), 310-330.

Fratiwi, N. J., Samsudin, A., Ramalis, T. R., Saregar, A., Diani, R., Irwandani, I., Rasmitadila, R., \& Ravanis, K. (2020). Developing MeMoRI on newton's 
laws: For identifying students' mental models. European Journal of Educational Research, 9(2), 699-708.

Giren, S. (2016). Early childhood education teachers' metaphors about play concept for preschoolers. Journal of Theory and Practice in Education, 12(1), 372388.

Grigorovitch, A. (2014). Children's misconceptions and conceptual change in physics education: The concept of light. Journal of Advances in Natural Sciences, 1(1), 34-39.

Grigorovitch, A. (2015). Teaching optics perspectives: 10-11 year old pupils' representations of light. International Education \& Research Journal, 1(3), 4-6.

Grigorovitch, A., \& Nertivich, D. (2017). Représentations mentales des élevés de 10-12 ans sur la formation des ombres. European Journal of Education Studies, 3(5), 150-160.

Herakleioti, E., \& Pantidos, P. (2016). The contribution of the human body in young children's explanations about shadow formation. Research in Science Education, 46(1), 21-42. https://doi.org/10.1007/s11165-0149458-2

Kaliampos, G., \& Ravanis, K. (2019). Thermal conduction in metals: Mental representations in 5-6 years old children's thinking. Jurnal Ilmiah Pendidikan Fisika Al-BiRuNi, 8(1), 19.

https://doi.org/10.24042/jipfalbiruni.v $8 \mathrm{i} 1.3737$

Latifah, S., Irwandani, I., Saregar, A., Diani, R., Fiani, O., Widayanti, W., \& Deta, U. A. (2018). How the PredictObserve-Explain (POE) learning strategy remediates students' misconceptions on Temperature and Heat materials? Journal of Physics: Conf. Series, 1171 (1), 012051.

Onen Ozturk, F., \& Aglarci, O. (2017). Prospective chemistry and science teachers' views and metaphors about chemistry and chemical studies. Eurasian Journal of Educational Research, 18(71), 119-140. http://dx.doi.org/10.14689/ejer.2017.7 1.7

Pereira, S., Maria José Rodrigues, M. J., \& Marques Vieira, R. (2020) Scientific literacy in the early years - practical work as a teaching and learning strategy. Early Child Development and Care, 190(1), 64-78. https://doi.org/10.1080/03004430.201 9.1653553

Piaget, J. (1971). Causalité et opérations. In J. Piaget \& R. Garcia (Eds), Les explications causales (pp. 11-140). Paris: PUF.

Ravanis, K. (1999). Représentations des élèves de l'école maternelle: Le concept de lumière. International Journal of Early Childhood, 31(1), 4853. https://doi.org/10.1007/BF03166731

Ravanis, K. (2012). Représentations des enfants de 10 ans sur le concept de lumière: perspectives piagétiennes. Schème-Revista Eletrônica de Psicologia e Epistemologia Genéticas, 4(1), 70-84.

Ravanis, K. (2017). Early childhood science education: state of the art and perspectives. Journal of Baltic Science Education, 16(3), 284-288.

Ravanis, K. (2018). How do we see the non luminous object? 12-13 years-old students' mental representations of vision. Jurnal Ilmiah Pendidikan Fisika Al-BiRuNi, 7(1), 1-9. https://doi.org/10.24042/jipfalbiruni.v $7 \mathrm{i} 1.2326$

Ravanis, K. Christidou, V., \& Hatzinikita, V. (2013). Enhancing conceptual change in preschool children's representations of light: A socio-cognitive approach. Research in Science Education, 43(6), 2257-2276. https://doi.org/10.1007/s11165-0139356-z 
Rodriguez, J., \& Castro, D. (2016). Changing 8-9 year-old pupil's mental representations of light: A metaphor based teaching approach. Asian Education Studies, 1(1), 40-46. https://doi.org/10.20849/aes.v1i1.30

Saregar, A., Irwandani, I., Abdurrahman, A., Parmin, P., Septiana, S., Diani, R., \& Sagala, R. (2018). Temperature and heat learning through SSCS model with scaffolding: Impact on students' critical thinking ability. Journal for the Education of Gifted Young Scientists, 6(3), 39-54. https://dergipark.org.tr/en/pub/jegys/is sue/39595/453460

Sotirova, E.-M. (2017). L'apprentissage en sciences expérimentales: la recherche et l'enseignement. European Journal of Education Studies, 3(12), 188-198. https://oapub.org/edu/index.php/ejes/a rticle/view/1292

Sotirova, E.-M. (2018). Cartes conceptuelles et formation des enseignants du primaire. Le cas de la vision dans l'optique géométrique. European Journal of Alternative Education Studies, 3(2), 22-31. https://oapub.org/edu/index.php/ejae/a rticle/view/1884

Tin, P. S. (2018). Élaboration expérimentale des représentions mentales des élèves de 16 ans sur les concepts thermiques. European Journal of Education Studies, $\quad 4(7), \quad$ 141-150. https://oapub.org/edu/index.php/ejes/a rticle/view/1676

Voutsinos, C. (2013). Teaching optics: Light sources and shadows. Journal of Advances in Physics, 2(2), 134-138. 